\title{
Implicit Options in Life Insurance: Valuation and Risk Management
}

\author{
By $\mathrm{Nadine}$ Gatzert and \\ $\mathrm{H}$ a t o $\mathrm{S}$ c h m e is e r, St. Gallen ${ }^{1}$
}

\section{Contents}

1. Introduction

2. Implicit options in participating life insurance contracts

2.1. Classification

2.2. Literature survey

3. Valuation and risk management of participating life insurance contracts

3.1. Valuation of contracts embedding rights to early exercise

3.2. Modeling a participating life insurance contract

3.3. Selected numerical examples

4. Summary

\section{Introduction}

Most life insurance policies are replete with implicit („embedded“) options that are generally of significant value. In the past, many of these options were offered free of charge, partly because traditional actuarial methods were incapable of appropriately pricing the options (see Santomero / Babbel, 1997, p. 242). When British Equitable Life had to stop taking new business in 2000 due to improper hedging of provided options, concern over embedded options intensified, especially regarding appropriate pricing and risk measurement of implicit options and risk management. However, the process of fair valuation requires an appropriate financial valuation model. Increasingly, actuaries are cooperating with financial economists to address this challenge.

Concern over implicit options is also reflected in recent regulatory processes; financial reporting now requires an evaluation of the market value of liabilities, and thus implicit options, at fair value. Determining the fair value of options is not only of special relevance in the context of solvency

1 Institute of Insurance Economics at the University of St. Gallen. Internet: www.ivwhsg.ch, e-mail address: nadine.gatzert@unisg.ch, hato.schmeiser@unsig.ch. 
tests (see, e.g., Solvency II in the European Union, Swiss Solvency Test in Switzerland), but also with respect to the International Financial Reporting Standards (IFRS). ${ }^{2}$ The growing interest in the field of valuation and risk management of embedded options in life insurance contracts is also demonstrated by the increasing number of scientific contributions to this field. Some recent contributions are concerned with risk-neutral valuation of participating life insurance contracts, a type common in the United Kingdom. ${ }^{3}$

The focus of this article is on participating life insurance contracts, i.e., contracts featuring death and survival benefits as well as participation in return generated by the insurer's investment portfolio. These types of contracts contain numerous guarantees and rights, such as a minimum interest rate guarantee, guaranteed annual or terminal surplus participation, a surrender option, and the paid-up option, among others. Past experience has consistently shown that these options can be very valuable and thus they can represent a significant risk to the insurance company. Hence, proper pricing and risk management of these options is very important. The aim of this paper is to illustrate the risk potential of implicit options within a life insurance contract that features the most common guarantees and options.

The rest of the paper is organized as follows. Section 2 contains a discussion of implicit options typically contained in participating life insurance contracts (2.1) and the relevant literature in this field (2.2). Section 3 first addresses assumptions for the valuation of insurance contracts embedding rights to early exercise (3.1) and then presents a model of a participating life insurance contract (3.2). Finally, selected numerical results for the valuation of the sample contract are given that illustrate the risk potential of the interaction of guarantees and options (3.3). Section 4 concludes.

\section{Implicit options in participating life insurance contracts}

This section provides an overview and classification of implicit options commonly included in participating life insurance contracts. In addition, a review is provided of literature covering the current state of the art for evaluating these options.

\footnotetext{
2 For an overview of recent developments and the fair valuation approach, see Jørgensen (2004), pp. $372-394$.

3 See Ballotta / Haberman / Wang (2006), pp. 97-121.
} 


\subsection{Classification}

In general, implicit options can be divided into either guarantees or rights. Table 1 summarizes implicit options typically included in participating life insurance contracts.

Table 1

Common guarantees and rights in participating life insurance contracts

\begin{tabular}{|l|l|}
\hline Implicit options & \\
\hline Guarantees & $\begin{array}{l}\text { Minimum guaranteed interest rate } \\
\text { Annual surplus participation } \\
\text { Terminal surplus participation }\end{array}$ \\
\hline Rights & $\begin{array}{l}\text { Paid-up option } \\
\text { Resumption option } \\
\text { Dynamic premium adjustment } \\
\text { Surrender option } \\
\text { Guaranteed annuity options }\end{array}$ \\
\hline
\end{tabular}

In many countries, certain guarantees and rights are required by law with the aim of protecting policyholders and to differentiate between offered products, e.g., mutual funds. Often, insurance companies are obliged to compound annual premium payments with at least a minimum guaranteed interest rate, which often is fixed by the government (in Germany, the guaranteed interest rate has been $2.75 \%$ since 1. 1. 2004; starting 1. 1. 2007, it will be reduced to $2.25 \%$ ).

Additionally, policyholders sometimes participate in the surplus generated by the insurer's investment portfolio. In this case, the policy reserve is compounded with the maximum of the guaranteed interest or a fraction of the investment surplus. The participation thus depends on the type of policy. The policyholder either participates directly in the investment return or according to a smoothing scheme. Policies in which annual surplus becomes part of the guarantee-thus increasing the maturity payment-are called cliquet-style contracts. Optionally, if at maturity the market value of assets exceeds the guaranteed maturity payment, terminal participation in the excess value can be provided. Contracts that do not feature annual surplus participation, but only a guaranteed maturity payment, are called point-topoint guarantees.

Policyholders also have various rights that are embedded in the contract design. Concerning premium payments, policyholders have the right (usually required by law) to stop the premium payments during the term of 
the contract; this is known as the „paid-up“ option. The contract is thereby not terminated but continues with reduced benefits. Some contracts embed the right to resume the premium payments later, thus increasing previously reduced benefits. Furthermore, policyholders can ask for a dynamic adjustment of premiums, i.e., premiums are increased from year to year by a fixed percentage. In contrast to the paid-up option, exercising the surrender option terminates the contract. The amount paid out to the policyholder depends on the reserves present at the exercise date as well as on cancellation costs.

Participating life insurance products can also include guaranteed annuity options, a common practice in U.S. tax-sheltered insurance products and in U.K. retirement savings. ${ }^{4}$ These options gained special interest when Equitable Life got in trouble due to neglect in pricing the time value. These kind of options provide the holder with the right to convert the policyholder's accumulated reserves to a life annuity at a fixed rate at maturity of the contract. The value of these options rises when interest rates fall, which corresponds to a put option on interest rates. When long-term interest rates began to fall in the $1990 \mathrm{~s}$, guaranteed annuity options gained significant value. Another factor to be considered in this respect is the longevity risk, which has not been accounted for a long time and only recently an increasing number of contributions is concerned with this issue.

In general, the present value of contracts depends on future payoffs of one or more variables and thus it becomes very complex to price these contracts appropriately. These options are meaningful as they can become very valuable and thus represent a significant risk to the insurance company. Hence, proper valuation, risk measurement, and risk management are highly important.

\subsection{Literature survey}

One common way to price insurance contracts at fair value is to use contingent claims pricing theory, which is based on the works of Black/ Scholes (1973) and Merton (1973). The particular adequacy of arbitrage models has been argued by Babbel / Merrill (1998), who provide a discussion of economic valuation models for insurers. The application of contingent claims theory to pricing equity-linked life insurance contracts was pioneered by Brennan / Schwartz (1976) and Boyle / Schwartz (1977). Participating life insurance contracts have been studied by Briys / de Varenne (1994, 1997), Grosen/Jørgensen (2000, 2002), Jensen/Jørgensen/Grosen (2001), Hansen/Miltersen (2002), Steffensen (2002), Bacinello (2003a, 2003b), Haberman / Ballotta / Wang (2003), Miltersen / Persson (2003), Tans-

\footnotetext{
4 See Boyle / Hardy (2003).
} 
kanen/Lukkarinen (2003), Gatzert/Kling (2005), Ballotta/Haberman / Wang (2006), Gatzert / Schmeiser (2006), and Kling / Richter / Ruß (2006).

Briys / de Varenne (1994) address guaranteed interest and annual surplus participation and evaluate insurance liabilities in a contingent claim framework. Taking the value of the insolvency put option into account, fair contract designs are derived and different regulatory measures are discussed.

Briys / de Varenne (1997) present a contract containing a point-to-point guarantee, that is, the company guarantees a maturity payment and an optional participation in the terminal surplus at expiration of the contract. The contract's market value in this model is basically a function of the guaranteed interest rate and the terminal surplus participation and thus only the guaranteed interest rate influences shortfall risk at maturity. Therefore, the authors introduce a model of stochastic interest rates. Based on a similar contract, Grosen/Jørgensen (2002) additionally consider the insurer's insolvency option and the impact of regulatory intervention, without using stochastic interest rates.

The life insurance contract studied by Grosen/Jørgensen (2000) features cliquet-style annual surplus participation. In this type of contract, the greater of the guaranteed interest rate or a fraction of the asset return is annually credited to the policy and in turn becomes part of the guarantee. A bonus account is introduced that serves for a smoothing mechanism for the participation in asset returns. The authors decompose the contract into a risk-free bond, a bonus part, and a surrender option.

Further work on contracts including a surrender option is done by Jensen / Jørgensen / Grosen (2001) and Tanskanen / Lukkarinen (2003), who determine fair pricing of contracts containing a guaranteed interest rate and different annual surplus participation schemes. Both papers thus propose a method for pricing contracts based on a finite difference scheme. Bacinello (2003a, 2003b) analyzes the surrender option in an Italian life insurance contract with single and periodic premiums, including mortality risk. Steffensen (2002) establishes a very general framework that includes surrender and paid-up options and suggests applying optimal intervention theory.

Hansen / Miltersen (2002) as well as Miltersen / Persson (2003) introduce a model of participating life insurance contracts with practical relevance in Denmark. Along with the interest rate guarantee and a smoothing surplus distribution mechanism similar to the one put forth by Grosen/Jørgensen (2000), terminal bonus is provided. Also, in this model, the policyholder pays an annual fee to the insurance company.

Gatzert/Kling (2005) propose a method that considers both pricing and risk measurement and thus increases information on insurance liabilities. They examine the effect of fair valuation on the insurer's risk situation, i.e., 
the actual likelihood and extent of a shortfall for fair contracts with the same market value. Key risk drivers are identified by comparing the results for different types of contracts, including cliquet-style and point-to-point guarantees.

Cliquet-style contracts with different smoothing mechanisms, as are common in the United Kingdom, are studied by Haberman/Ballotta/Wang (2003) and Ballotta/Haberman/Wang (2006). In this type of contract, the liabilities annually earn the greater of a guaranteed interest rate or a predetermined fraction of, e.g., the arithmetic or geometric average of the last period returns of the insurer's reference portfolio. Ballotta/Haberman / Wang (2006) also focus on the default option's effect on fair pricing.

Gatzert / Schmeiser (2006) develop a model framework for a contract that includes an interest-rate guarantee, cliquet-style annual surplus participation, and offers paid-up and resumption options. The valuation is not based on assumptions about particular exercise strategies, but an upper bound to the option price is provided that is independent of the policyholder's exercise behavior. Using this approach, the impact of guaranteed interest rate, annual surplus participation, and investment volatility on the values of the premium payment options is analyzed.

Kling/Richter/Ruß (2006) present a general framework for contracts containing cliquet-style guarantees, which are common in Germany, and evaluate them by taking into consideration the German regulatory framework. They analyze the interaction of various contract parameters such as management decisions concerning surplus participation rates and guaranteed interest rates.

Guaranteed annuity options have been analyzed by Milevsky / Promislow (2001), Boyle / Hardy (2003), and Haberman / Ballotta (2003), among others. Milevsky/Promislow (2001) model the actuarial hazard rate or force of mortality as a stochastic variable. Boyle / Hardy (2003) consider unit-linked contracts and discuss the effect of different risk management strategies. Haberman / Ballotta (2003) also treat unit-linked contracts and compare the results of two different term structure models.

\section{Valuation and risk management of participating life insurance contracts}

This section discusses, first, assumptions made in the valuation of the policyholder's option to exercise the life insurance contract before its maturity. Second, a model set up for a sample contract is presented and, finally, selected numerical examples with a special focus on premium payment options are presented. 


\subsection{Valuation of contracts embedding rights to early exercise}

The evaluation of insurance contracts including rights to early exercise such as premium payment or surrender options is complex, as it strongly depends on assumptions of policyholder exercise behavior and the underlying asset model. These kind of options are American-style, and since exercise dates are discrete in time (monthly or annually, depending on the premium payment frequency), they belong to the class of Bermudans.

Table 2 outlines possible assumptions concerning policyholder exercise behavior and the valuation process.

\section{Table 2}

Preliminary assumptions for the valuation of insurance contracts

\begin{tabular}{|c|c|}
\hline Exercise behavior & Valuation model \\
\hline $\begin{array}{l}\text { - Rational exercise (optimal stopping } \\
\text { problem) } \\
\text { - Exercise probabilities (estimate from } \\
\text { historical data, expected exercise be- } \\
\text { havior is modeled) } \\
\text { - Worst-case scenario (upper bound to } \\
\text { the option price) }\end{array}$ & $\begin{array}{l}\text { - Deterministic interest rates, determi- } \\
\text { nistic cash flows } \\
\text { - Stochastic interest rates, deterministic } \\
\text { cash flows } \\
\text { - Deterministic interest rates, stochastic } \\
\text { cash flows } \\
\text { - Stochastic interest rates, stochastic } \\
\text { cash flows }\end{array}$ \\
\hline \multicolumn{2}{|c|}{$=>$ Valuation of life insurance contracts } \\
\hline
\end{tabular}

Valuation of contracts with embedded options of early exercise is strongly linked to policyholder exercise behavior and the model framework. In the following, three possible approaches are discussed. ${ }^{5}$ In finance theory, Bermudan options are priced by considering an option holder who exercises in a way that maximizes his or her option value based on the information available at the exercise date. This leads to an optimal stopping problem, which can be solved numerically with Monte Carlo simulation techniques. ${ }^{6}$

If one presumes that policyholders do not act rationally in the sense explained above, but instead make decisions for personal reasons, a reasonable model for their expected exercise behavior needs to be developed and integrated in the valuation process. The contracts can then be priced using exercise probabilities. ${ }^{7}$ Alternatively, to evaluate options for a given portfo-

5 See Kling / Ruß/Schmeiser (2006) for an overview of possible exercise strategies in the case of paid-up options in German government-subsidized pension products.

6 See Andersen (1999), pp. 5-32 and Douady (2002), pp. 314-328.

7 E.g., Albizzati/Geman (1994), pp. 616-637, propose a concept of exercise probabilities in the case of a surrender option within a unit-linked life insurance contract common in France. For the case of a combined option consisting of a lump-sum 
lio of insurance contracts, historical data can be used to estimate exercise probabilities. However, this approach is problematic since it is not certain that future behavior will follow past patterns.

As it is not entirely clear how policyholders make their decisions, a third approach provides an upper bound to the option price for any exercise strategy. This is done by evaluating the worst case for the insurance company, which is when the policyholder exercises randomly and hits the maximum value. The evaluation procedure leads to a higher value than when following an admissible exercise strategy, where only information available at the exercise date is used. Such an approach is the safest an insurer can follow, as it shows the maximal hazard and risk potential of the option.

Concerning the underlying asset framework, the degree of complexity of the valuation model must be defined. ${ }^{8}$ In particular, cash flows and interest rates can each be modeled either stochastically or deterministically. Table 2 sets out valuation models in the order of increasing complexity. The first case is the simplest, as both factors are either known or modeled deterministically. The case of stochastic cash flows and stochastic interest rates in the last row is the most complex and general model.

Stochastic cash flows in participating life insurance contracts are driven by the insurer's investment portfolio. Geometric Brownian motion is often used as a benchmark model for the asset process. Alternatively, e.g., Lévy processes as driving noise can be integrated in the model. For a model of stochastic interest rates, the Vasicek model or the Cox, Ingersoll and Ross model have been used, among others. ${ }^{9}$

\subsection{Modeling a participating life insurance contract}

In the following section, a model of a participating life insurance contract is discussed that includes the main implicit options and is based on the framework developed in Gatzert/Schmeiser (2006). Therefore, the focus is on premium payment options, which are evaluated based on the worst-case scenario (left column, third row in Table 2) of policyholder exercise behavior to obtain an upper bound to the option price. The valuation model is defined by deterministic interest rates and stochastic cash flows (right column, third row in Table 2). ${ }^{10}$

option and an early retirement option in deferred unit-linked annuities, see Dillmann / Ruß (2003).

8 See also Babbel/Merrill (1998), pp. 1-17, for a detailed discussion of different valuation models.

9 For an overview, see, e.g., Albrecht / Maurer (2005), pp. 465-504.

10 The model framework is laid down in detail in Gatzert/Schmeiser (2006) and was part of Nadine Gatzert's presentation at the annual meeting of „Deutscher Verein für Versicherungswissenschaft e. V." in Berlin 2006. This section contains new nume- 
The model participating insurance contract is laid out in Table 3.

Table 3

The participating life insurance contract decomposed into building blocks

\begin{tabular}{|l|l|l|}
\hline „Basic“ & $\begin{array}{l}\text { Annual premium payments } \\
\text { Death and survival benefit } \\
\text { Minimum guaranteed interest rate } \\
\text { Annual surplus participation (cliquet-style) }\end{array}$ & $\begin{array}{l}\text { Basic contract } \\
\text { including } \\
\text { two options }\end{array}$ \\
\hline "Paid-up“ & Paid-up option & Additional options \\
\hline "Resumption“ & Resumption option & \\
\hline
\end{tabular}

The contract set forth in Table 3 is decomposed into building blocks. The basic contract already includes two typical options, i.e., a minimum interest rate guarantee and a cliquet-style annual participation in the returns of the insurer's investment portfolio, which is credited to the policy reserve. Thus, the basic contract features guaranteed death and survival benefits. The policyholder makes annual premium payments during the term of the contract. Next, the basic contract is expanded successively. First, the policyholder additionally receives the paid-up option, i.e., the right to stop the premium payments exactly once and without resuming the payments later. Second, the resumption option is included, where the policyholder is also allowed to resume the payments once after making the contract paid-up.

Starting with the basic contract, the financial market model is based on a generalized Black-Scholes framework, where the insurer's investment portfolio follows a geometric Brownian motion. Mortality risk is assumed to be diversifiable, i.e., by writing a sufficiently large number of similar policies, the law of large numbers holds and this risk can be handled using average U.S.-population mortality data from Bell/Miller's (2002) cohort life table. Therefore, we believe the mortality development in time to be stochastically independent from the returns of the insurer's investment portfolio.

As is common in actuarial practice, guaranteed death and survival benefits are calculated using the actuarial equivalence principle. This principle requires that the present value of future benefits must equal the present value of future premium payments; thus the present value calculus is based on discounted „real-world“ expected values. For given constant annual premiums and the guaranteed interest rate as a technical discount rate, the (constant) benefits are obtained. For the survival benefit at maturity, the

rical examples that are not contained in Gatzert/Schmeiser (2006) to illustrate the risk potential of typical implicit options in participating life insurance contracts under different parameter configurations. 
policy reserve is paid out, which, in addition to the guaranteed payment, contains annual surplus participation rates.

When the policyholder makes the contract paid-up, the contract is not terminated but instead continues with reduced benefits, which depend on the policy reserve present at the exercise date. The adjusted benefits are derived from the actuarial equivalence principle by taking the policy reserve as a one-time payment in a „new “ contract. $^{11}$ The guaranteed interest rate and annual surplus participation remain the same as before making the contract paid-up, since these guarantees were promised at inception for the whole term of the contract.

\subsection{Selected numerical examples}

This section contains numerical results for the participating life insurance contract set out in Table 3 . In particular, the effect of the basic contract's parameters on the value of the premium payment options is shown. The aim is to illustrate the complex interaction of various implicit options in common contract designs and the impact on the contract's value and risk.

The numerical valuation is conducted in two steps. First, only the basic contract is considered and the parameters guaranteed interest rate - denoted by $g$ - and annual surplus participation rate - denoted by $\alpha$ - are calibrated such that the present value of expected premium payments is equal to the present value of benefits, i.e., the basic contract has a net present value of zero. ${ }^{12}$ This basic contract can be called „fair" since the two options included in it are completely covered by the annual premium payments. Determination of the present value is made using the concept of risk-neutral valuation. ${ }^{13}$

Second, given the parameters found in the first step, the contract's value (in $t=0$ ) is determined when the policyholder obtains additional options (see Table 3). The net present value of the contract including the additional premium payment options is calculated by subtracting the present value of expected premium payments from the present value of future benefits. This difference is no longer zero, as the annual premium payments do not suffice to cover the costs of extra options in addition to the minimum interest rate guarantee and annual surplus participation. Thus, when exercising the paid-up option, the future cash flows from the original contract are exchanged for cash flows from a new contract with reduced benefits but without premium payments. Exercising is beneficial if the present value of the new contract is greater than the present value of the old contract.

11 For details, see, e.g., Wolfsdorf (1986), p. 219.

12 Hence $g$ and $\alpha$ are fixed for the whole term of the contract.

13 See, e.g., Bjørk (2004). 
In the numerical examples, the premium payment options are valued under the worst-case scenario so as to obtain an upper bound to the option price for all types of exercise strategies. The valuation model uses deterministic interest rates and stochastic cash flows in order to identify the effect of stochastic cliquet-style annual surplus participation on the value of the premium payment options.

For this contract, the policyholder pays annual premiums of $€ 1000$. The risk-free interest rate is $4 \%$. A parameter set for a reference contract is fixed as follows:

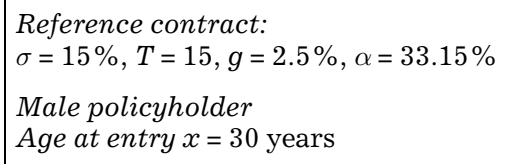

For $\alpha=33.15 \%$, the net present value of the basic contract is zero, i.e., the basic contract is fair. Figure 1 shows the basic contract and paid-up option values at time $t=0$. Bars with hatched shading represent the value of the basic contract; the plain bars represent the additional value of the paid-up option at $t=0$ when offered on top of the guarantees in the basic contract.

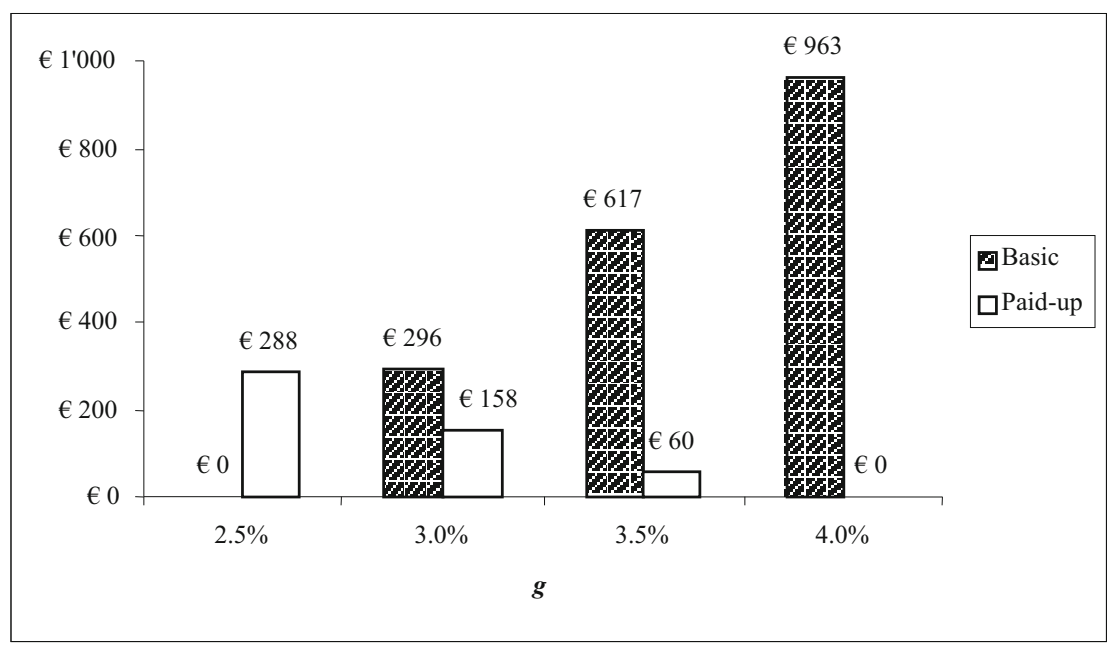

Figure 1: Basic contract and additional paid-up option values at $t=0$ for $\sigma=15 \%, T=15, \alpha=33.15 \%$ 
Figure 1 displays the results for different values of the guaranteed interest rate $g$, starting with a fair basic reference contract ( $g=2.5 \%$, zero net present value). In this case, the value of the paid-up option is not covered by the annual premium payments (in contrast to the options embedded in the basic contract). Instead, its maximum value is $€ 288$.

The figure illustrates some central aspects of the interaction between various implicit options, in particular counterbalancing effects. For example, raising the guaranteed interest rate, ceteris paribus, leads to an increase in the basic contract's value, but to a decrease in the value of the paid-up option. Hence, with higher guarantees, there are less states where exercising the paid-up option is beneficial. When $g$ equals the risk-free interest rate of $4 \%$, the paid-up option is worthless, as the insurance contract provides the same safe conditions as the market. Similar results are obtained for the annual surplus participation rate and asset volatility, i.e., with increasing $\sigma$ and $\alpha$ the value of the basic contract increases whereas the value of the paid-up option decreases.

Under the assumption that the policyholder will exercise the paid-up option when it is of maximum value, the option values set out in Figure 1 need to be paid at $t=0$ by the policy buyer in addition to the annual premium payment of $€ 1000$ in order to create fair contract conditions (i.e., shareholder and policyholder obtain a net present value of zero when signing the contract). The option pricing framework used here is based on the assumption that the insurer can always restrain the given guarantees and rights embedded in the contracts. Hence, there is no default risk concerning the policyholder's benefits. From the insurance company's viewpoint, it is important to receive (at least) the fair price of the embedded options so that adequate risk management measures may be undertaken or bought. Given an arbitrage-free market, option prices should coincide with the price of any risk management measure that ensures that the contract's guarantees and rights can be fulfilled. Even though risk-neutral pricing techniques used to calculate the option prices in Figure 1 assume the possibility of time-continuous hedging strategies, this need not be the risk management measure the insurer actually conducts. A whole range of risk management measures would be equally suitable, including, for example, an (increase) of equity capital, contingent capital, and reinsurance.

To analyze the impact of a fair basic contract design on premium payment option values, the annual surplus participation rate is recalibrated each time the reference contract is modified to keep the basic contract fair. The following analysis always starts with a basic contract with a net present value of zero, thus ensuring comparability. Numerical results for paid-up and resumption options are contained in Table 4. 
Table 4

Option values in $€$ and as a percentage of the present value of the expected premium payments given an exercise at maximum value (the results related to $t=0$ )

\begin{tabular}{|c|c|c|c|}
\hline Contract figures & Basic & Paid-up & Resumption \\
\hline $\begin{array}{l}\text { Reference contract: } \\
\sigma=15 \%, T=15, g=2.5 \%, \alpha=33.15 \% \text {, } \\
\text { male, } x=30\end{array}$ & $€ 0$ & $€ 288(5.62 \%)$ & $€ 299(5.56 \%)$ \\
\hline $\begin{array}{l}\text { Modification regarding the reference } \\
\text { contract: } \\
g=1.5 \%, \quad \alpha=40.23 \%\end{array}$ & $€ 0$ & $€ 399(7.69 \%)$ & $€ 415(7.61 \%)$ \\
\hline$\sigma=10 \%, \quad \alpha=45.10 \%$ & $€ 0$ & $€ 266(5.10 \%)$ & $€ 276(5.04 \%)$ \\
\hline$\alpha=33.28 \%$ & $€ 0$ & $€ 600(7.77 \%)$ & $€ 624(7.65 \%)$ \\
\hline$\alpha=33.15 \%$ & $€ 0$ & $€ 227(4.67 \%)$ & $€ 236(4.66 \%)$ \\
\hline$\alpha=33.14 \%$ & $€ 0$ & $€ 295(5.72 \%)$ & $€ 305(5.65 \%)$ \\
\hline
\end{tabular}

Notes: $\sigma=$ asset volatility; $g=$ guaranteed interest rate; $\alpha=$ annual participation rate; $x=$ policyholder's age at entry.

Starting with the reference contract figures, the first row contains option values for $\sigma=15 \%, T=15$, and $g=2.5 \%$ (see also first bar in Figure 1 ). As before, in the first step, the annual surplus participation rate is calibrated to ensure fair contract conditions, i.e., the basic contract has a net present value of zero and guaranteed interest rate and annual surplus participation are thus covered by the premium payments. When the paid-up option is added to the basic contract, the contract's net present value becomes positive. Hence, for the reference contract, the value of the additional paid-up option at inception is worth at most $€ 288$ within the considered exercise scenario. This makes up $5.62 \%$ of the present value of corresponding expected premium payments.

If the resumption option is offered on top of the paid-up option, the policyholder gains the right to resume the payments once after stopping them. This additional right raises the contract's total value from $€ 288$ to $€ 299$. Thus, the resumption option leads to a marginal increase of $€ 11$. This might be due to the reasons for making the contract paid-up in the first place, namely, „unattractive“ contract conditions. Hence, offering more flexibility leads to only a moderate increase in contract value.

In case the guaranteed interest rate is lowered to $g=1.5 \%$, the annual surplus participation rate must be increased to $40.23 \%$ to keep the basic contract fair (second row in Table 4). Interestingly, in this case the value of the paid-up option shows a strong increase to $€ 399$, even though $\alpha$ is raised at the same time, which shows that $g$ is the dominant risk driver in fair 
contracts. Hence, the paid-up option becomes more valuable the lower the guaranteed interest rate. This is important as it shows the counterbalancing effects of options contained in the basic insurance contract on the value of premium payment options.

Surprisingly, a decrease of asset volatility from $15 \%$ to $10 \%$ (third row in Table 4) has only a minor impact on reducing the paid-up option value when $\alpha$ is raised to keep the basic contract fair. This shows that, in our example, the annual surplus participation rate has a stronger effect on the value of the paid-up option than does volatility. This appears reasonable as $\alpha$ controls how much of the volatility is transferred to the policy.

When the contract term is increased from $T=15$ to 30 years (fourth row in Table 4), the annual surplus participation coefficient remains almost unchanged since the fairness condition (concerning the financial part of the contract) does not depend on the time to maturity due to independent return increments and the constant risk-less interest rate. ${ }^{14}$ However, the effect of an increase in the contract term on the paid-up option value is tremendous: the option values are more than doubled, now making up $7.77 \%$ of the present value of expected premium payments. This is because, on average, a longer contract term creates many more cases where an exercise of the paid-up option will be valuable to the policyholder.

For policyholders who are older at entry, the paid-up option values decrease due to lower survival probabilities (see fifth row in Table $4, x=50$ ): options can be exercised only if the policyholder is alive. For the same reason, and as shown in the last row in Table 4, female policyholders have higher option values.

To sum up, premium payment options in participating life insurance contracts can become of significant value, particularly in the cases of lower guaranteed interest rates and annual surplus participation rates, younger and female policyholders, and longer contract terms. The interaction of guarantees included in the basic contract and the premium payment options is complex. For example, a decrease in the guaranteed interest rate leads to a decrease in the basic contract value, but to an increase in the paid-up option value. For fair basic contracts, a reduction in volatility requires an increase of the annual participation rate, and yet this still does not lead to a significant reduction of the paid-up option value. The most important option is the paid-up option. Offering more flexibility by including the resumption option leads to only a moderate increase in contract value.

14 See Ballotta / Esposito / Haberman (2005), p. 5. 


\section{Summary}

This article summarized and explained common implicit options in typical life insurance contracts and discussed the relevant literature concerned with fair valuation. Guarantees and options typically found in these contracts include a minimum interest rate guarantee, surplus participation, a surrender option, premium payment options, and guaranteed annuity options. A contract can be called fair if its net present value is zero, which implies that the present value of expected premium payments equals the present value of future benefits. The article also pointed out problems associated with the valuation concerning policyholder exercise behavior and the choice of the valuation model. For the numerical analysis, a common contract design was considered that included a guaranteed interest rate and stochastic annual surplus participation, as well as paid-up and resumption options. Valuation was conducted by giving an upper bound to the option price based on Gatzert/Schmeiser (2006). Using this approach, one main observation is the complexity in valuation when option values depend on policyholder exercise behavior. Furthermore, the contract's total value strongly depends on the interaction between the different guarantees and options included in it. In particular, counterbalancing effects concerning the value of the different options in the contract should be taken into consideration regarding questions of product design and risk management.

\section{References}

Albizzati, M.-O/Geman, H. (1994): Interest Rate Risk Management and Valuation of the Surrender Option in Life Insurance Policies, in: Journal of Risk and Insurance, $61(4), 616-637$.

Albrecht, P./Maurer, R. (2005): Investment- und Risikomanagement, 2. Auflage, Schäffer-Poeschel, Stuttgart.

Andersen, L. (1999): A Simple Approach to the Pricing of Bermudan Swaptions in the Multi-Factor LIBOR Market Model, in: Journal of Computational Finance, 3(2), $5-32$.

Avellaneda, M. (ed.) (2002): Quantitative Analysis in Financial Markets, Volume III, World Scientific Publishing Co., Singapore.

Babbel, D. F. / Merrill, C. (1998): Economic Valuation Models for Insurers, in: North American Actuarial Journal, 2(3), 1-17.

Bacinello, A. R. (2003a): Pricing Guaranteed Life Insurance Participating Policies with Annual Premiums and Surrender Option, in: North American Actuarial Journal, 7(3), $1-17$.

Bacinello, A. R. (2003b): Fair Valuation of a Guaranteed Life Insurance Participating Contract Embedding a Surrender Option, in: Journal of Risk and Insurance, 70(3), $461-487$. 
Ballotta, L. / Esposito, G. / Haberman, S. (2005): The IASB Insurance Project for Life Insurance Contracts: Impact on Reserving Methods and Solvency Requirements, Actuarial Research Paper No. 162, Cass Business School, City of London.

Ballotta, L. / Haberman, S. / Wang, N. (2006): Guarantees in With-Profit and Unitized With-Profit Life Insurance Contracts: Fair Valuation Problem in Presence of the Default Option, in: Journal of Risk and Insurance, 73(1), 97-121.

Bell, F. C. / Miller, M. L. (2002): Tables for the United States Social Security Area 1900-2100, in: Actuarial Study No. 116. Social Security Administration, US. Download (2006 / 04 / 01): www.ssa.gov / OACT / NOTES / actstud.html.

Bjørk, T. (2004): Arbitrage Theory in Continuous Time. Oxford University Press, New York.

Black, F. / Scholes, M. (1973): The Pricing of Options and Corporate Liabilities, in: Journal of Political Economy, 81(3), 637-654.

Boyle, P. P. / Hardy, M. R. (2003): Guaranteed Annuity Options, in: ASTIN Bulletin, $33(2), 125-152$.

Boyle, P. P. / Schwartz, E. S. (1977): Equilibrium Prices of Guarantees Under EquityLinked Contracts, in: Journal of Risk and Insurance, 44(4), 639-660.

Brennan, M. J. / Schwartz, E. S. (1976): The Pricing of Equity-Linked Life Insurance Policies with an Asset Value Guarantee, in: Journal of Financial Economics, 3(3), $195-213$.

Briys, E./de Varenne, F. (1994): Life Insurance in a Contingent Claim Framework: Pricing and Regulatory Implications, in: Geneva Papers on Risk and InsuranceTheory, 19(1), $53-72$.

Briys, E. / de Varenne, F. (1997): On the Risk of Insurance Liabilities: Debunking Some Common Pitfalls, in: Journal of Risk and Insurance, 64(4), 673-694.

Dillmann, T. / Ruß, J. (2003): Implicit Options In Life Insurance Contracts-From Option Pricing to the Price of the Option, in: Proceedings of the $7^{\text {th }}$ Conference of the Asia-Pacific Risk and Insurance Association 2003, Bangkok (Thailand).

Douady, R. (2002): Bermudan Option Pricing with Monte-Carlo Methods, in: Avellaneda, M. (ed.): Quantitative Analysis in Financial Markets, Volume III, World Scientific Publishing Co., Singapore, 314-328.

Gatzert, N./Kling, A. (2005): Analysis of Participating Life Insurance Contracts: A Unification Approach, in: Working Papers on Risk Management and Insurance No. 18, University of St. Gallen.

Gatzert, N. / Schmeiser, H. (2006): Assessing the Risk Potential of Premium Payment Options in Participating Life Insurance Contracts, in: Working Papers on Risk Management and Insurance No. 22, University of St. Gallen.

Grosen, A. / Jørgensen, P. L. (2000): Fair Valuation of Life Insurance Liabilities: The Impact of Interest Rate Guarantees, Surrender Options, and Bonus Policies, in: Insurance: Mathematics and Economics, 26(1), 37-57.

Grosen, A./Jørgensen, P. L. (2002): Life Insurance Liabilities at Market Value: An Analysis of Insolvency Risk, Bonus Policy, and Regulatory Intervention Rules in a Barrier Option Framework, in: Journal of Risk and Insurance, 69(1), 63-91.

Haberman, S. / Ballotta, L. (2003): Valuation of Guaranteed Annuity Conversion Options, in: Insurance: Mathematics and Economics, 33 (1), $87-108$. 
Haberman, S. / Ballotta, L. / Wang, N. (2003): Modelling and Valuation of Guarantees in With-Profit and Unitised With-Profit Life Insurance Contracts, in: Actuarial Research Paper No. 146, Cass Business School, City of London.

Hansen, M. / Miltersen, K. R. (2002): Minimum Rate of Return Guarantees: The Danish Case, in: Scandinavian Actuarial Journal, 2002(4), 280-318.

Jensen, B./Jørgensen, P. L. / Grosen, A. (2001): A Finite Difference Approach to the Valuation of Path Dependent Life Insurance Liabilities, in: The Geneva Papers on Risk and Insurance Theory, 26(3), 57-84.

Jørgensen, P. L. (2004): On Accounting Standards and Fair Valuation of Life Insurance and Pension Liabilities, in: Scandinavian Actuarial Journal, 2004(5), 372 - 394.

Kling, A. / Richter, A. / Ruß, J. (2006): The Interaction of Guarantees, Surplus Distribution, and Asset Allocation in With Profit Life Insurance Policies, to appear in: Insurance: Mathematics and Economics.

Kling, A. / Ruß, J. / Schmeiser, H. (2006): Analysis of Embedded Options in Individual Pension Schemes in Germany, to appear in: Geneva Risk and Insurance Review.

Merton, R. C. (1973): Theory of Rational Option Pricing, in: Bell Journal of Economics and Management Science, 4(1), $41-183$.

Milevsky, M. A. / Promislow, S. D. (2001): Mortality Derivatives and the Option to Annuitize, in: Insurance: Mathematics and Economics, 29(3), 299-318.

Miltersen, K. R./Persson, S.-A. (2003): Guaranteed Investment Contracts: Distributed and Undistributed Excess Return, in: Scandinavian Actuarial Journal, 2003(4), $257-279$.

Santomero, A. M. / Babbel, D. F. (1997): Financial Risk Management by Insurers: An Analysis of the Process, in: Journal of Risk and Insurance, 64(2), 231-270.

Steffensen, M. (2002): Intervention Options in Life Insurance, in: Insurance: Mathematics and Economics, 31(1), 71-85.

Tanskanen, A. J. / Lukkarinen, J. (2003): Fair Valuation of Path-Dependent Participating Life Insurance Contracts, in: Insurance: Mathematics and Economics, 33(3), $595-609$.

Wolfsdorf, K. (1986): Versicherungsmathematik, Teil 1: Personenversicherung, Teubner.

\begin{abstract}
Participating life insurance contracts typically contain various types of implicit options. These implicit options can be very valuable and can thus represent a significant risk to insurance companies if they practice insufficient risk management. Options become especially risky through interaction with other options included in the contracts, which makes their evaluation even more complex. This article provides a comprehensive overview and classification of implicit options in participating life insurance contracts and discusses the relevant literature. It points out the potential problems particularly associated with the valuation of rights to early exercise
\end{abstract}


due to policyholder exercise behavior. The risk potential of the interaction of implicit options is illustrated with numerical examples by means of a life insurance contract that includes common implicit options, i.e., a guaranteed interest rate, stochastic annual surplus participation, and paid-up and resumption options. Valuation is conducted using risk-neutral valuation, a concept that implicitly assumes the implementation of risk management measures such as hedging strategies.

\section{Zusammenfassung}

Überschussbeteiligte Lebensversicherungsverträge enthalten zahlreiche implizite Optionen, die sich in die Kategorien Garantien und Wahlrechte unterteilen lassen. Solche Optionen können für den Kunden sehr wertvoll sein und stellen im Falle einer nichtauskömmlichen Prämienbemessung und eines unzureichenden Risikomanagements ein erhebliches Risiko für Lebensversicherungsunternehmen dar. Die Komplexität im Rahmen der Bewertung von Optionen in Lebensversicherungsverträgen beruht vor allem auf den vielschichtigen Wechselwirkungen zwischen den in den Verträgen enthaltenen Garantien und Wahlrechten. Der vorliegende Beitrag nimmt zunächst eine Systematisierung zentraler Garantien und Wahlrechte vor und gibt einen vergleichenden Überblick zum Stand der Literatur im Rahmen der Bewertung von Optionen in überschussbeteiligten Lebensversicherungsverträgen. Des Weiteren werden Implikationen erörtert, die mit den spezifischen Ausübungsrechten des Versicherungsnehmers verbunden sind; hierzu gehört zum einen der Fall der Vertragsstornierung sowie die Situation, in der der Versicherungsnehmer sein Recht zur Beitragsfreistellung wahrnimmt. In einer numerischen Analyse werden unter Verwendung des Konzepts der risikoneutralen Bewertung Lebensversicherungsverträge betrachtet, die neben einer Mindestverzinsungszusage und einer garantierten Überschussbeteiligung dem Versicherungsnehmer erlauben, sich beitragsfrei stellen zu lassen, aber auch zu einem späteren Zeitpunkt nach erfolgter Beitragsfreistellung wieder Einzahlungen in den Vertrag vorzunehmen. 